\title{
Conversion to organic farming decreases the vulnerability of dairy farms
}

\author{
Maëlys Bouttes $^{1}$ (D) $\cdot$ Niels Bize ${ }^{1} \cdot$ Goulven Maréchal $^{2} \cdot$ Guillaume Michel $^{3} \cdot$ Magali San Cristobal $^{4} \cdot$ Guillaume Martin $^{1}$
}

Accepted: 18 February 2019/Published online: 8 March 2019

(C) INRA and Springer-Verlag France SAS, part of Springer Nature 2019

\begin{abstract}
In the context of the European crisis in conventional milk production, conventional farms potentially dissimilar to organic farming models are converting to organic. This raises the issue of farm vulnerability during and after this conversion, i.e. the farm's ability to respond to the effects of technical, climatic and economic risks. Our objective was to show whether and how dairy farm vulnerability can decrease during and after conversion to organic farming. We surveyed a sample of 12 dairy farms in Brittany, France, from 2008 (their last year conventional) to 2013. Our method considered farm vulnerability a function of the initial level of and trend in farm self-sufficient milk productivity, economic efficiency, net profitability per worker and independence from European common agricultural policy (CAP) subsidies. We related these vulnerability variables to explanatory variables that illustrated farm exposure to climatic and economic variability and farming practices. The results show that nearly all farms improved their economic efficiency (11/12), about two thirds improved their self-sufficient milk productivity (8/12) and profitability per worker (7/12), and half improved their independence from CAP subsidies (6/12). Farms had diverse vulnerability patterns, with trade-offs between the initial situation and the trend followed during the conversion, and among vulnerability variables. We identified two main adaptation strategies: (i) pasture-based farms that were similar to organic farming models when conventional and that did not change much during the conversion, and (ii) farms based on maize and feed concentrates when conventional that drastically changed. The latter farms had the greatest decrease in vulnerability and improved their self-sufficient milk productivity, profitability per worker, economic efficiency and independence from CAP subsidies. Overall, variability in climatic and economic conditions had less influence on vulnerability than farming practices. Here, we showed for the first time that changing farming practices by converting to organic farming can be a powerful mechanism for reducing farm vulnerability.
\end{abstract}

Keywords Organic agriculture $\cdot$ Dairy farming $\cdot$ Farm management $\cdot$ Resilience $\cdot$ Robustness $\cdot$ Sustainability

\section{Introduction}

Farmers encounter an increasingly turbulent context characterised by volatility in the prices of inputs and outputs (Wright 2011) and more frequent extreme climatic events

Maëlys Bouttes and Niels Bize contributed equally to this work.

Maëlys Bouttes

maelys.bouttes@gmail.com

1 AGIR, INPT, INP-PURPAN, INRA, Université de Toulouse, 31320 Auzeville, France

2 FRAB Bretagne, 35510 Cesson-Sevigné, France

3 GAB 22, 22193 Plérin, France

4 DYNAFOR, INRA, INPT, INPT-EI PURPAN, Université de Toulouse, 31326 Castanet-Tolosan, France
(IPCC 2013). In Europe, since the increased liberalisation of the dairy sector in the 2000 s, great instability in the milk market has challenged many dairy farmers (Brehon 2009). After the first major crisis in 2009, it was unclear when conventional milk prices would recover, so farmers began to consider alternative markets. In France, some farmers perceived that entering organic markets was a promising strategy, as the price of organic raw milk was higher and remained relatively constant over time. In 2009, the specifications for organic farming were standardised in European Union countries, which resulted in fewer restrictions for French organic farms. Thus, in Brittany, the highest-producing dairy region in France (Agreste 2015), 90 dairy farmers began their conversion in 2009, compared to 2-18 conversions per year from 2004 to 2008 (Despeghel, FRAB, personal communication).

When converting to organic farming, farmers implement management practices according to organic specifications 
from the beginning of their conversion. However, they are paid organic milk prices only after 18 or 24 months, depending on the type of conversion chosen (synchronous or asynchronous conversion of land and the herd). Thus, initiating a technical transition in a turbulent economic context is particularly challenging. This raises the issue of the vulnerability of dairy farms during and after their conversion to organic farming. Vulnerability depends on (i) the exposure of agricultural systems to internal (mainly technical failures) and external (mainly climate- and market-related) risks, i.e. their degree, duration and extent; (ii) the sensitivity of agricultural systems to these risks, i.e. the degree to which they are affected; and (iii) their ability to respond and adapt to, or recover from, these risks (Smit and Wandel 2006). Farmers and farm consultants need updated and contextual information on the most successful adaptation strategies to reduce farm vulnerability during and after conversion to organic farming.

Several studies analysed farm trajectories over time to identify drivers of change (García-Martínez et al. 2009; Chantre and Cardona 2014) and relate farming practices to the resulting performances (Falconnier et al. 2015). They did not focus on the conversion to organic farming, however, which often requires extensive system redesign and results in distinct changes in the patterns of farm performances. These studies considered strategic changes and consequently used multiyear time steps (up to 14 years in García-Martínez et al. (2009)), whereas year-to-year tactical adaptations are essential to capture the timeframe of the conversion to organic farming. Most of these studies focused on a single performance (i.e. productivity, economic efficiency or profitability) and failed to address trade-offs among these performances that explain farm vulnerability. In contrast, studies focused on the conversion to organic farming address mainly farmers' motivations and doubts during the conversion period (Flaten et al. 2006; Lamine and Bellon 2009; Cranfield et al. 2010). While this is a key determinant of farmers' vulnerability during and after their conversion to organic, it fails to encompass the entire issue, which may also include the adaptation strategies and farming practices that farmers implemented (Fig. 1). Farming practices are key determinants of organic dairy farm vulnerability (Bouttes et al. 2018b). Their adaptations may result in multiple changes in farm performance patterns (Reed et al. 2013; Lebacq et al. 2015). When converting to organic farming, the trade-offs between farm self-sufficient milk productivity and economic efficiency that illustrate organic dairy farm vulnerability (Bouttes et al. 2018a, 2018b) could change drastically. Other key components of farm vulnerability are profitability per worker and independence from European common agricultural policy (CAP) subsidies, as profitability of the least vulnerable farms should not depend too much on CAP subsidies, the amount of the latter being subject to uncertainty in the future.

Our objective was to show whether and how dairy farm vulnerability can decrease when converting to organic farming, and the adaptation strategies that decrease this vulnerability the most (e.g. changes in agricultural diversity, land use intensity - stocking rate, percentage of cropping area in the farmland, etc.-and herd-management intensityconcentrate use, age at first calving, etc.) (Fig. 1). From a sample of dairy farms in Brittany, France, we analysed relations between farmers' adaptation strategies when converting to organic farming and the resulting farm vulnerability.

\section{Materials and methods}

\subsection{Case study farms}

We performed this study in Brittany, north-western France, from 2008 to 2013. In 2008, organic dairy farms represented
Fig. 1 Adaptation strategies dairy farmers use during conversion to organic farming that result in different levels of vulnerability: (1) storing silage maize for cow feed, (2) increased focus on grazing, and (3) green feeding brought by the farmer each day. Sources: Maëlys Bouttes $(1,3)$ [INRA], Matthieu Chanel (2) [Agrobio 35]

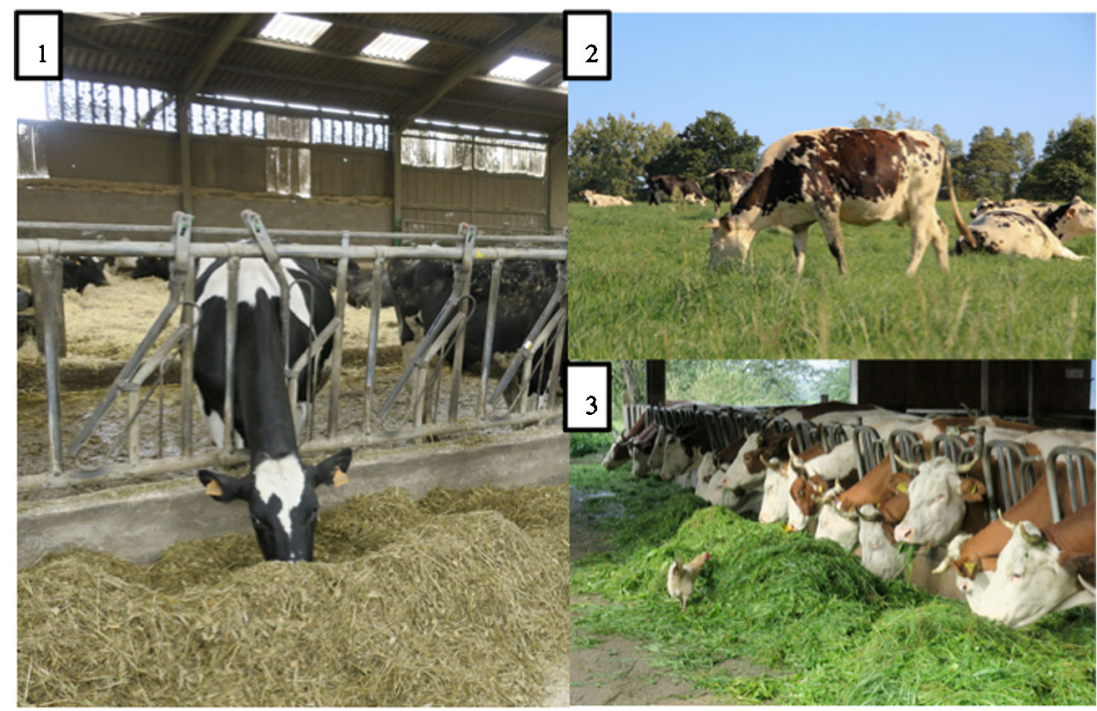


$1.8 \%$ of dairy farms (255 farms) in Brittany compared to $3.3 \%$ in 2013 (456 farms). We annually surveyed 12 dairy cattle farms for 5 years. Data were collected on key aspects of farming systems: geographic location, land use, herd structure and management (feeding, reproduction), animal production, income and costs. All 12 farms began their conversion in 2009. Conversion to organic dairy farming is organised in two ways: synchronous conversion of land and the herd (24 months) or asynchronous conversion of land (18 months) and the herd (6 months, starting in month 12 of land conversion). The 12 farms were initially selected because they chose different adaptation strategies for the conversion. Five and seven farms implemented synchronous and asynchronous conversions, respectively. The farms were distributed throughout Brittany, which exposed them to a diversity of climatic conditions (mainly exposure to droughts). Farms also differed in their initial farming system (i.e. when farming conventional), with a diversity in farm size (land area, herd size), land accessible for grazing, land use intensity (percentage of maize cropping in the area used to feed livestock, stocking rate, milk productivity per ha), herd management intensity (concentrate use, milk productivity per cow), and as a result in self-sufficiency for livestock feeding and self-sufficient milk productivity (Fig. 2).

\subsection{Statistical analysis}

Statistical analysis was performed to (i) assess farm vulnerability to climatic, economic and technical risks and (ii) explain this vulnerability as a function of the climatic and economic context and farming practices over time. We chose an adaptation of the method developed by Martin et al. (2017) because it considers dynamics of interactions between changes in farming practices and farm vulnerability over several years. These dynamics are keys when analysing conversion to organic farming, which implies extensive changes in farming-practice and farm-vulnerability variables over the years. We also wanted to consider several farm-vulnerability variables together, which is possible using this method.

We first summarised the information from repeated measurements of each vulnerability and farming-practice variable over time into two parameters. We assumed that initial farm performances and farming practices strongly illustrated farm vulnerability and farmers' strategies before conversion to organic (i.e. conventional farming). During conversion, farm-vulnerability variables are expected to vary as farmers implement the technical transition through trial and error and as ecosystems slowly adapt to new farming practices (e.g. plant composition changes in pastures, less maize production, etc). As we focused on general trends, we thus estimated the slope of the linear regression of raw measurements over time for each vulnerability and farming-practice variable. We also focused on the initial measured value and slope of the linear regression to discuss the initial state of farms and their overall evolution from conventional to organic farming. Unlike Martin et al. (2017), we did not analyse intercepts or residuals of variables. For explanatory variables

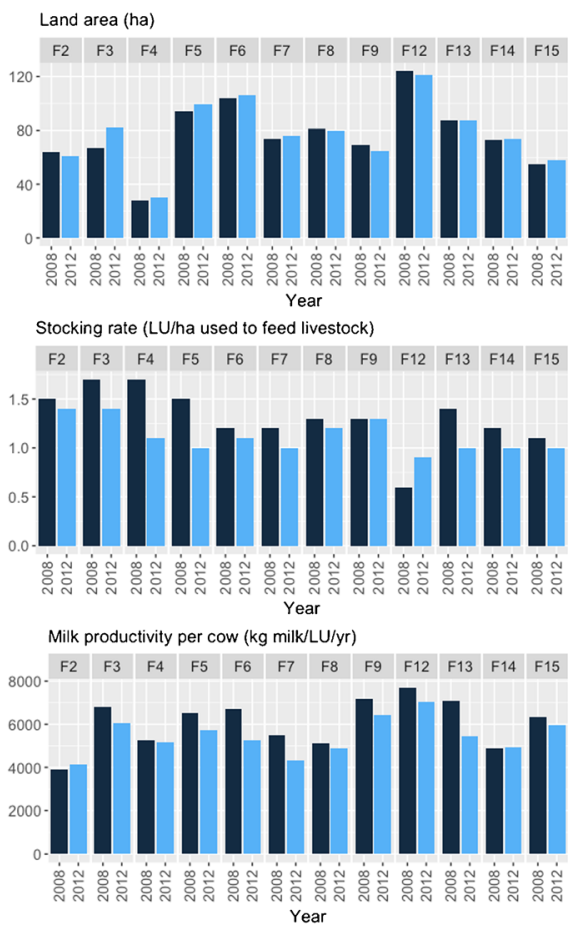

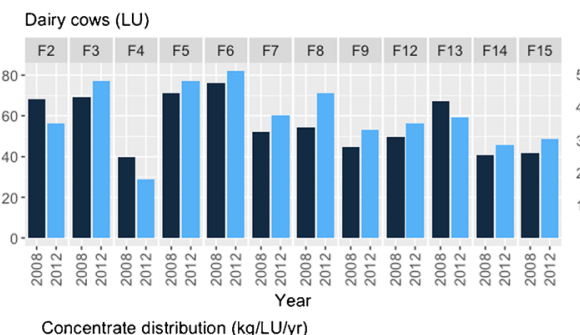

Concentrate distribution $(\mathrm{kg} / \mathrm{LU} / \mathrm{yr})$

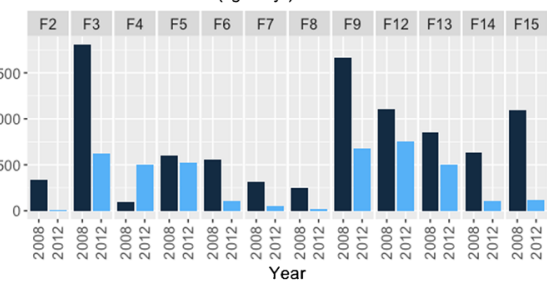

Milk productivity per hectare (kg milk/ha used to feed livestock/yr)

\begin{tabular}{l|l|l|l|l|l|l|l|l|l|l|l} 
F2 & F3 & F4 & F5 & F6 & F7 & F8 & F9 & F12 & F13 & F14 & F15
\end{tabular} \begin{tabular}{c|c|c|}
$6000-$ \\
$4000-$ \\
$2000-$
\end{tabular}

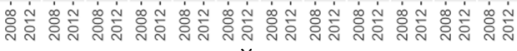
Year
Maize cropping (\% area used to feed livestock) \begin{tabular}{l|l|l|l|l|l|l|l|l|l|l|l|} 
F2 & F3 & F4 & F5 & F6 & F7 & F8 & F9 & F12 & F13 & F14 & F15 \\
\hline
\end{tabular} 20.

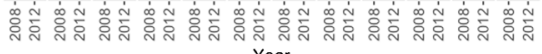
Self-sufficiency for feed (\%) \begin{tabular}{|l|l|l|l|l|l|l|l|l|l|l|l|} 
F2 & F3 & F4 & F5 & F6 & F7 & F8 & F9 & F12 & F13 & F14 & F15 \\
\hline
\end{tabular} 25--

Self-sufficient milk productivity ( $\mathrm{kg}$ milk/ha used to feed livestock/yr) \begin{tabular}{l|l|l|l|l|l|l|l|l|l|l|l|} 
F2 & F3 & F4 & F5 & F6 & F7 & F8 & F9 & F12 & F13 & F14 & F15
\end{tabular}

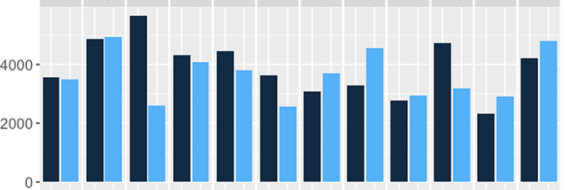

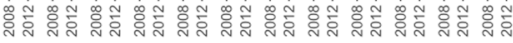
Year

Fig. 2 Key features of the sample farms in 2008 and 2012. LU livestock unit 
illustrating the climatic and economic context, however, we did extract residuals of linear regressions of raw measurements as an indicator of farm exposure to climatic and economic variability. Among all possible combinations, farm vulnerability to climatic and economic variability was minimised by combining high initial values (i.e. indicating "good" initial performances) with a stable or increasing trend (i.e. indicating stability or improvement) for all vulnerability variables.

In a second step, we used partial least squares (PLS) regression to relate multiple new farm-vulnerability variables (initial value and trends) to new explanatory variables that illustrated farm exposure to climatic and economic variability and evolution in farming practices over time. The PLS regression created components (linear combinations of variables) by maximising the square covariance between components of explanatory variables and components of vulnerability variables. PLS regression was performed using the statistical package mixOmics (González et al.; Lê Cao et al. 2009) in R software.

\subsection{Choice of vulnerability and explanatory variables}

Based on a review of the literature and focus groups consisting of farm advisers and dairy farmers, we identified variables that illustrate farm vulnerability, climatic and economic variability and farming practices. For vulnerability variables, farm self-sufficient milk productivity (i.e. milk production generated by animal feed produced on-farm by using internal farm resources) was selected because it reflects the real productivity of the farm resources and it is highly influenced by changes in farming practices, especially land use and cow diets. Organic feed inputs are more expensive than those in the conventional sector. To consider the higher prices of organic feed inputs, which must be used efficiently, we selected economic efficiency, i.e. the amount of economic output produced from a given amount of operational costs (i.e. the total of intermediate costs for production: seeds, feed, etc.). Net economic profitability per worker before interest, depreciation and amortisation was also included. As a decrease in farm vulnerability assumes financial independence from CAP subsidies to generate a profit, we chose a fourth variable called "independence from subsidies" which represents the proportion of CAP subsidies in total farm profit. Thus, vulnerability variables were as follows:

- Farm self-sufficient milk productivity, i.e. generated by animal feed produced on-farm by using internal farm resources ("Productivity", kg per year per ha of usable agricultural area) $=$ production of milk $\times$ selfsufficiency in animal feeding (the latter corresponding to on-farm animal feed production divided by the total animal feed consumption on a dry-matter basis)

- Economic efficiency of production ("Efficiency", unitless $)=($ gross product - operational costs $) /$ operational costs

- Net economic profitability per worker before interest, depreciation and amortisation ("Profitability", K€ per worker) = gross operating surplus/annual work unit

- Independence from CAP subsidies ("Independence", unitless $)=1-($ overall CAP subsidies/gross operating surplus)

To represent farming practices, three groups of variables illustrated land use intensity, herd management intensity and the level of system diversity. We expected that these three aspects would be modified during conversion to organic farming towards a decrease in intensity and an increase in diversity. These three types of variables have been used to explain the vulnerability of organic dairy systems (Bouttes et al. 2018a, 2018b). Ultimately, we illustrated these key aspects with 10 explanatory variables:

- Milk production per cow ("MilkCow, kg milk per cow per year)

- Stocking rate calculated as the number of livestock units (1 LU = grazing equivalent of one adult dairy cow producing $3000 \mathrm{~kg}$ of milk annually, without additional concentrated foodstuffs) per ha of the area used to feed livestock ("StockingRate", LU per ha)

- Percentage of heifers in the herd ("Heifers", \%)

- Percentage of maize cropping in the area used to feed livestock ("Maize", \%) = forage maize area $\times 100 /$ (utilised agricultural area - grain crop area)

- Percentage of pasture in the area used to feed livestock ("Pastures", \%) = pasture area $\times 100 /$ (utilised agricultural area - grain crop area)

- Percentage of farm area with pure-stand legume cropping ("Legumes", \%)

- Percentage of grazed area in the area used to feed livestock ("GrazedArea", \%) = grazed area $\times 100 /$ (utilised agricultural area - grain crop area)

- Percentage of green feeding area in the area used to feed livestock ("GreenFeeding", \%) = area used for harvesting fresh fodder $\times 100 /$ (utilised agricultural area - grain crop area)

- Amount of concentrates distributed per livestock unit ("ConcDistrib", kg per LU per year)

- Shannon index of diversity in farm land use; the more diverse the land-use types on the farm, the higher the index ("ShannonLand", unitless)

Among the explanatory variables, we discarded the initial measurement of the percentage of grazed area in the area used 
to feed livestock, as the data for this variable were collected in 2009 rather than 2008.

Farm exposure to climatic variability was assessed with the following six variables:

- Earliness of the growing season, i.e. sum of degree days from 1 February to 1 April of each year ("Earliness", ${ }^{\circ} \mathrm{C}$ per year)

- Heat stress on crop and forage plants, i.e. number of days per year with a mean temperature greater than $25{ }^{\circ} \mathrm{C}$ ("Heatstress", number of days per year)

- Mean daily effective rainfall in spring, summer, autumn and winter ("WaterSpring", "WaterSummer", "WaterAutumn", "WaterWinter", mm per year)

Finally, farm exposure to economic variability was assessed with the mean milk price paid to farmers each year ("MilkPrice", $€$ per year). The integrated fuel and energy price index for each year (IDELE 2017) was initially considered; however, it was impossible to collect per-farm data. Because it did not help distinguish farms, we excluded it from the list of variables of the PLS regression.

\section{Results and discussion}

\subsection{Overview of farm vulnerability patterns: Diversity and trade-offs}

Vulnerability variables measured at the conventional stage, i.e. in 2008 , before conversion to organic, varied greatly among farms. Farm self-sufficient milk productivity ranged from 2304 to $5677 \mathrm{~kg}$ milk $/ \mathrm{ha} /$ year $($ mean $=3910 \mathrm{~kg}$ milk/ha/year, CV $=25 \%$ ) due to very different levels of stocking rate (in the range $0.6-1.7 \mathrm{LU} / \mathrm{ha}$ ), self-sufficiency for animal feeding (in the range $50-91 \%$ ) and milk productivity per cow (in the range 3893-7713 kg milk/LU/year). Economic efficiency ranged from $0.9-3.1$ (mean $=1.7, \mathrm{CV}=38 \%$ ). Economic profitability per worker ranged from 14 to $58 \mathrm{~K}$ $€ /$ year (mean $=32 \mathrm{~K} € /$ year, $\mathrm{CV}=46 \%$ ). Independence from CAP subsidies ranged from 0.4 to 0.7 (mean $=0.6, \mathrm{CV}=$ $18 \%)$. Overall, farms showed different initial vulnerability patterns, highlighting different trade-offs among vulnerability variables. For example (Fig. 3), farm F4 was not among the most efficient (1.4) or profitable farms (18 K€/year), but it tended to be among the most productive $(5677 \mathrm{~kg}$ milk/ha/ year) thanks to a high stocking rate $(1.7 \mathrm{LU} / \mathrm{ha}$ against a mean $=1.3 \mathrm{LU} / \mathrm{ha}$ ) and a level of self-sufficiency for animal feeding beyond the average (77\% against $69 \%$ ). It was also among the most independent from CAP subsidies (0.7). In contrast, farm F12 focused on economic efficiency (2.5) and yet was not among the most profitable $(25 \mathrm{~K} € /$ year) or productive $(2778 \mathrm{~kg}$ milk/ha/year) due to a stocking rate far

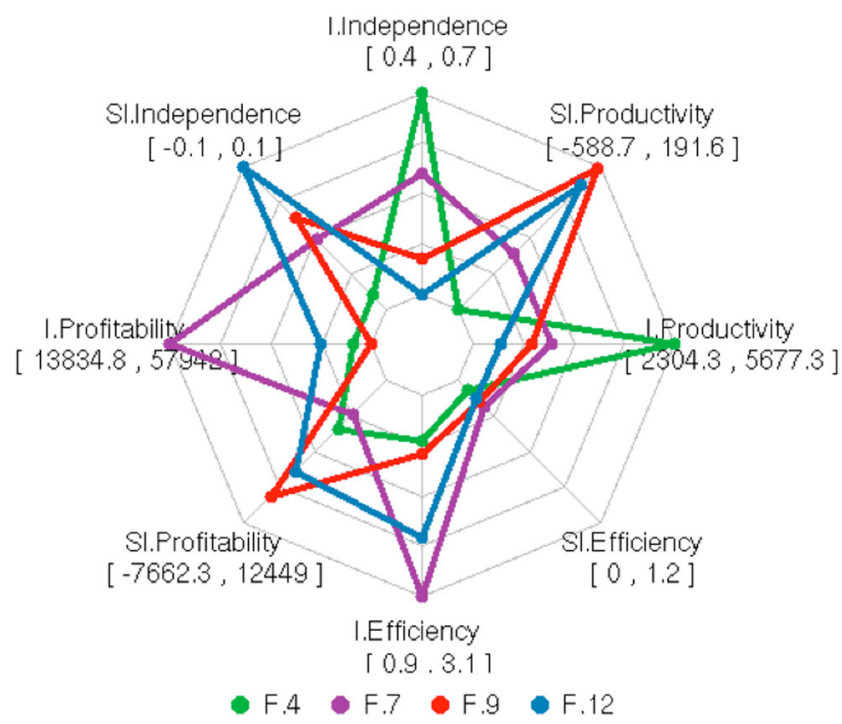

Fig. 3 Radar plot of standardised vulnerability variables for four farms. Vulnerability variables are initial values (I) and slopes (Sl) of farm productivity, economic efficiency, economic profitability and independence from subsidies. Values in brackets indicate the range of observed values

beyond the average $(0.6 \mathrm{LU} / \mathrm{ha}$ against $1.3 \mathrm{LU} / \mathrm{ha})$. It was also the least independent from CAP subsidies (0.4). Farm F7 had another pattern, with the best balance among economic variables (efficiency of 3.1, profitability per worker of $58 \mathrm{~K} € /$ year and independence from CAP subsidies of 0.6), although it was among the least productive farms (3619 kg milk/ha/year) due to a stocking rate and milk production per cow beyond the average. Farm F9 seemed vulnerable for all four variables when conventional because it was among the lowest in economic efficiency (1.5), profitability per worker (14 K€/year), independence from CAP subsidies (0.5) and self-sufficient milk productivity ( $3300 \mathrm{~kg}$ milk/ha/year). The latter was due to that farm having the lowest level of self-sufficiency for animal feeding (50\%) in spite of a rather high milk productivity per cow (7156 kg milk/LU/year). These trade-offs among vulnerability variables at the conventional stage illustrated differences in initial levels of vulnerability among farms and reflected differences in farming strategies.

Analysis of the trends in vulnerability variables showed that all farms reduced their vulnerability for at least one variable when converting to organic farming. Four farms (F9, F12, F14, F15) improved all four vulnerability variables during and after conversion to organic farming. For three farms (F2, F3, F13) and two farms (F6, F8), improvements were limited to three and two vulnerability variables, respectively. For farms F4, F5 and F7, only one vulnerability variable improved. These changes differed among farms depending on the vulnerability variable. Most farms (10) decreased their stocking rate (with a mean decreasing trend by $0.24 \mathrm{LU} / \mathrm{ha}$ over the 5 years) and their milk productivity per cow (with a mean decreasing trend by $795 \mathrm{~kg}$ milk LU over the 5 years) to 
increase their self-sufficiency for animal feeding. This resulted in eight farms increasing their self-sufficient milk productivity by $7-192 \mathrm{~kg}$ milk/ha/year, while four others decreased it by 196-589 kg milk/ha/year. As a result, farm self-sufficient milk productivity in 2012 ranged from 2558 to $4932 \mathrm{~kg}$ milk/ha/ year $($ mean $=3621 \mathrm{~kg}$ milk/ha/year, $\mathrm{CV}=23 \%)$. This narrower range compared to the conventional stage (2374 kg milk/ha/year against $3373 \mathrm{~kg}$ milk/ha/year) was mainly related to the narrower range of stocking rate $(0.5 \mathrm{LU} /$ ha against $1.1 \mathrm{LU} / \mathrm{ha})$ and of milk productivity per cow $(2928 \mathrm{~kg}$ milk/LU/year against $3820 \mathrm{~kg}$ milk/LU/year) following the conversion to organic. Eleven farms increased their efficiency by $0.07-1.17$ every year, while one slightly decreased it by 0.01 every year. Economic efficiency in 2012 ranged from 1.5 to 6.5 (mean $=3.3, \mathrm{CV}=47 \%)$. Seven farms increased their profitability per worker by $4.7-12.4 \mathrm{~K} € /$ year, while four decreased it by $0.5-7.7 \mathrm{~K} € /$ year. Profitability per worker in 2012 ranged from 12 to $84 \mathrm{~K} € /$ year (mean $=42 \mathrm{~K} € /$ year, $\mathrm{CV}=$ $45 \%$ ). Six farms increased their independence from CAP subsidies by $0.01-0.06$ every year, while six others decreased it by $0.01-0.06$ every year. Independence from CAP subsidies in 2012 ranged from 0.1 to 0.7 (mean $=0.5, \mathrm{CV}=28 \%$ ).

Different trade-offs among vulnerability variables among farms best illustrate the changes in vulnerability patterns during and after conversion to organic farming. Four farms with contrasting patterns were selected to illustrate these trade-offs. Farm F4 displayed a trend towards higher vulnerability for three vulnerability variables (Fig. 3). Its self-sufficient milk productivity and independence from CAP subsidies, which were the best in the sample when conventional, decreased to $2579 \mathrm{~kg}$ milk/year $($ slope $=-589 \mathrm{~kg}$ milk/year $)$ and 0.5 (slope $=-0.05$ ), respectively. The former dropped due to decrease in stocking rate (-35\% between 2008 and 2012) and self-sufficiency for animal feeding ( $-26 \%$ between 2008 and 2012). Economic efficiency and profitability per worker of farm 4 were low when conventional, and did not increase greatly during and after conversion to organic. Its efficiency increased (slope $=0.07$ ) to 2.0 and profitability per worker decreased (slope $=-0.8 \mathrm{~K} € /$ worker/year) to $12 \mathrm{~K} € /$ worker/ year. Farm F7 also appeared to follow a trend towards higher vulnerability for the three variables, but had a more balanced trade-off among these variables than farm F4 (Fig. 3). Starting with a moderate self-sufficient milk productivity and independence from CAP subsidies, the former slightly decreased (slope $=-287 \mathrm{~kg}$ milk/year) to $2558 \mathrm{~kg}$ milk/ha/year due to a decrease in stocking rate $(-17 \%$ between 2008 and 2012) and milk productivity per cow $(-21 \%$ between 2008 and 2012) and the latter stabilised at 0.4. Even though its economic variables were initially in the upper range, its economic vulnerability increased, as illustrated by the decrease in profitability per worker (slope $=-2.9 \mathrm{~K} € /$ worker/year) to $36 \mathrm{~K}$ $€ /$ worker/year and the small increase in efficiency (slope $=$ 0.2 ) to 3.5. In contrast, farm F9 had the largest decrease in vulnerability, which decreased for all four variables: selfsufficient milk productivity was initially in the moderate range and increased (slope $=177 \mathrm{~kg}$ milk/year) to $4542 \mathrm{~kg}$ milk/year thanks to a sharp increase in self-sufficiency for animal feeding (+54\% between 2008 and 2012); efficiency was initially in the lower range and slightly increased (slope $=0.16$ ) to 1.8 ; profitability per worker was initially the lowest in the sample and increased (slope $=8.6 \mathrm{~K} € /$ worker/year) to $46 \mathrm{~K} € /$ worker $/$ year; and independence from CAP subsidies was initially low and increased (slope $=0.01$ ) to 0.6. Like farm F9, farm F12 showed a decrease in vulnerability for the four variables; however, the trade-off among these variables differed. Farm F12, initially in the lower range for self-sufficient milk productivity and independence from CAP subsidies, increased the former (slope $=87 \mathrm{~kg}$ milk/year) to $2929 \mathrm{~kg}$ milk/ha/year by increasing its stocking rate (+50\% between 2008 and 2012), and this slightly increased the latter (slope $=0.06$ ) to 0.4 . Its economic efficiency increased to 2.3. It had low profitability per worker in the beginning which increased (slope $=5.2 \mathrm{~K} € /$ worker/ year) to $41 \mathrm{~K} € /$ worker/year.

These four farms highlight the diversity in vulnerability patterns among the farms and the trade-offs between the initial situation and the trend followed during and after conversion, as well as among vulnerability variables. Overall, nearly all farms followed a conversion trend towards increased efficiency (11/12), two thirds towards increased self-sufficient milk productivity $(8 / 12)$, nearly as many towards increased profitability per worker (7/12), and half towards increased independence from CAP subsidies (6/12). This is related to the tradeoffs between the initial situations (i.e. when conventional) and changes during and after conversion. When initial independence from CAP subsidies was low, it was much easier to increase it during the conversion to organic. Similarly, the most profitable farms when conventional did not increase their profitability per worker much during and after the conversion. Mainly based on grazing, these farms (F5, F7, F8) focused on maximising profit rather than productivity, as Coquil et al. (2014) observed for dairy farms when analysing trends in their autonomy. Thus, these farms did not have much room for improvement, except in obtaining the organic price for milk.

Additionally, trade-offs among vulnerability variables were clear, yet differed among farms depending on their initial situation and the adaptation strategy implemented for the conversion. In most cases, it was not possible to simultaneously maximise self-sufficient milk productivity, efficiency, profitability per worker and independence from CAP subsidies. Only four farms decreased their vulnerability for all four variables. Previous studies showed similar results and the inability to simultaneously maximise farm productivity and economic performances in organic dairy (Bouttes et al. 2018b), conventional dairy (Doole and Romera 2015) and sheep farms (Ripoll-Bosch et al. 2012). Farmers' objectives for obtaining a given trade-off depend on their motivations for converting to 
organic farming (Cranfield et al. 2010): some do so to improve their adaptive capacity (Bouttes et al. 2018a), while others are motivated mostly by health and safety concerns (Cranfield et al. 2010). Thus, the diversity in farmers' motivations for converting to organic farming may explain the trade-offs observed among vulnerability variables. For example, a farm that focuses on productivity may meet this objective at the individual cow level ( $\mathrm{kg}$ milk/cow/year), but at the expense of farm profitability per worker. This kind of trade-off analysis helps to understand farming system functioning and supports decision-making when managing multiple objectives (Kanter et al. 2016). The results are relevant as a "discussion support" (Klapwijk et al. 2014) because they enable farmers and farm advisers to engage in deeper discussions about adaptation strategies during and after conversion to organic that are based on farmers' objectives.

\subsection{Strategies to convert to organic farming and respective vulnerability}

We investigated whether explanatory variables that illustrate farm exposure to climatic and economic variability and farming practices over time could predict vulnerability variables for self-sufficient milk productivity, economic efficiency, profitability and independence from CAP subsidies. Components 1 and 2 (Fig. 4) of the PLS regression between vulnerability variables and explanatory variables provided insights. For component 1, the slopes of self-sufficient milk productivity and profitability per worker were highly correlated, indicating that increasing self-sufficient milk productivity throughout the conversion to organic enabled an increase in profitability per worker. For components 1 and 2, the slope of profitability per worker was negatively correlated with initial levels of efficiency and profitability per worker. Thus, profitability per worker increased most when farms initially were not profitable or efficient. The slope of independence from CAP subsidies was negatively correlated with the initial levels of independence from CAP subsidies and self-sufficient milk productivity. Thus, independence from CAP subsidies increased most when farms had low self-sufficient milk productivity or were highly independent from CAP subsidies when conventional.

The largest increase in farm self-sufficient milk productivity and profitability per worker corresponded to farms that initially had a high percentage of maize, a low percentage of pasture and a high use of concentrates. When conventional, these farms were intensive and focused on productivity because they were based on silage maize and purchased concentrates to feed the cows. These systems were the most dissimilar to organic farming models, which tend to rely mainly on pastures. During conversion, these farms increased the percentage of pasture at the expense of the percentage of maize the most and decreased concentrate use the most. Thus, these farms sharply revised their strategy for grazing and selfsufficient animal feeding. The increase in farm selfsufficient milk productivity and profitability per worker was also related to farm exposure to climatic variability. It was highest on farms with the least exposure to variability in effective rainfall in spring.

Conversely, the decrease in farm self-sufficient milk productivity and profitability per worker corresponded to farms that initially had a high percentage of pasture, a low percentage of maize, and a low use of concentrates. These farms had conventional strategies similar to organic farming standards and were already profitable and productive when conventional. During their conversion, these farms did not greatly change the percentage of maize, the percentage of pasture or the use of concentrates. Conversion to organic farming did not transform these farms or
Fig. 4 Partial least square regression of vulnerability variables (orange) based on explanatory variables (blue): residuals $(\mathrm{R})$ of climate and economic conditions, and initial values (I) and slopes (Sl) of farming practices. Components 1 and 2 show relationships of the variables along these dimensions. Full names of variables are provided in Sect. 2.3

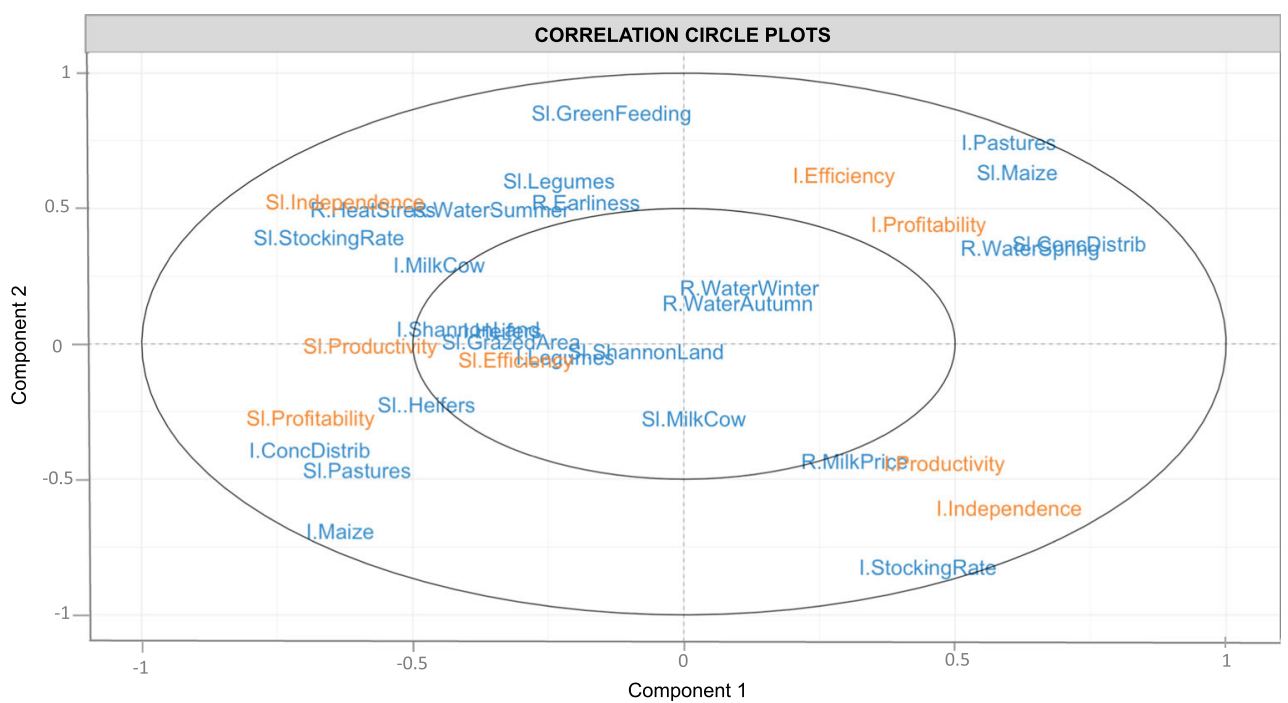


significantly decrease their vulnerability to the variables considered. The decrease in farm self-sufficient milk productivity and profitability per worker was also related to climatic variability and was highest on farms with the greatest exposure to variability in effective rainfall in spring.

The largest increases in farm independence from CAP subsidies corresponded to the least productive and independent farms when conventional. This was due to an increase in the stocking rate, which was low when conventional yet composed of highly productive cows. These farms had the greatest exposure to variability in climatic conditions, especially earliness of the growing season, heat stress and effective rainfall in summer.

Conversely, farms that were initially the most productive and independent from CAP subsidies had the largest decrease in independence from CAP subsidies during conversion to organic farming. These farms had low milk production per cow and a high stocking rate when conventional, the latter decreasing during the conversion to organic. These farms had the least exposure to variability in climatic conditions, especially earliness of the growing season, heat stress and effective rainfall in summer.

Analysis of the distribution of individual data points in the PLS (Fig. 5) identified the farms that decreased their vulnerability most or least during the conversion to organic farming according to the vulnerability variables, and the position of these farms with respect to farming practices and climatic and economic variability. The farms with the largest decrease in vulnerability (F9, F12, F14 and F15) were initially dissimilar to organic farming models in the Brittany context. They increased their self-sufficient milk productivity (mean increasing trend $=155 \mathrm{~kg}$ milk/ha/year changing the range from $2304-4228$ to $2892-4799 \mathrm{~kg}$ milk/ha/year), efficiency (mean increasing trend $=0.62$ every year changing the range from $1-$
2.4 to $1.8-5.1$ ), profitability per worker (mean increasing trend $=8.9 \mathrm{~K} € /$ worker/year changing the range from 14-39 to $41-84 \mathrm{~K} €$ /worker/year) and independence from CAP subsidies (mean increasing trend $=0.03$ every year changing the range from $0.4-0.5$ to $0.4-0.7$ ). They decreased their vulnerability for all four variables during the conversion to organic. They decreased their initially high percentage of maize in the farmland (mean decreasing trend $=6.3 \%$ every year changing the range from $14-51$ to $0-19 \%$ ) in favour of increasing the percentage of pasture, which was initially low (mean increasing trend $=4.1 \%$ every year changing the range from $49-86$ to $81-100 \%$ ). Use of concentrates shifted to more cost-effective management (mean decreasing trend $=141 \mathrm{~kg} / \mathrm{LU} /$ year changing the range from $632-1669$ to $110-751 \mathrm{~kg} / \mathrm{LU} /$ year), but the extent of the decrease did not decrease much milk production per cow (mean decreasing trend $=86 \mathrm{~kg} \mathrm{milk} / \mathrm{ha} /$ year changing the range from $4920-7046$ to $4896-7713 \mathrm{~kg}$ $\mathrm{milk} / \mathrm{ha} / \mathrm{year})$. Their initial strategy was based on a low stocking rate $(0.6-1.3 \mathrm{LU} / \mathrm{ha})$ that changed $(0.9-1.3 \mathrm{LU} / \mathrm{ha}$ although the mean trend was nil) as the percentage of heifers in the herd increased slightly (from 12-31 to 16-32\%), except on one farm. These farms had the least exposure to variability in effective rainfall in spring (range $=-1.44$ to $0.85 \mathrm{~mm} /$ year, mean $=-0.36, \mathrm{CV}=70 \%$ ). These farms used conversion to organic farming as a way to change from a cropping-based, feed-input-dependent and productivity-centred strategy towards a strategy focused on grazing and self-sufficient animal feeding ( $+35 \%$ between 2008 and 2012). Starting from vulnerable situations, these changes resulted in a decrease in vulnerability for these farms during the conversion.

Conversely, some farms (F4, F5 and F7) tended to increase their vulnerability during their conversion to organic. When conventional, these farms were the most similar to organic farming models in the Brittany context. They decreased their profitability per worker (mean decreasing trend $=1.7 \mathrm{~K}$
Fig. 5 Partial least square (PLS) regression showing individual data points (farms by number). Block X (left) corresponds to explanatory variables (economic and climatic exposure, farming practices), while block Y (right) corresponds to vulnerability variables (efficiency, profitability, productivity and independence). Farms in green and red reduced their vulnerability most and least during the conversion, respectively

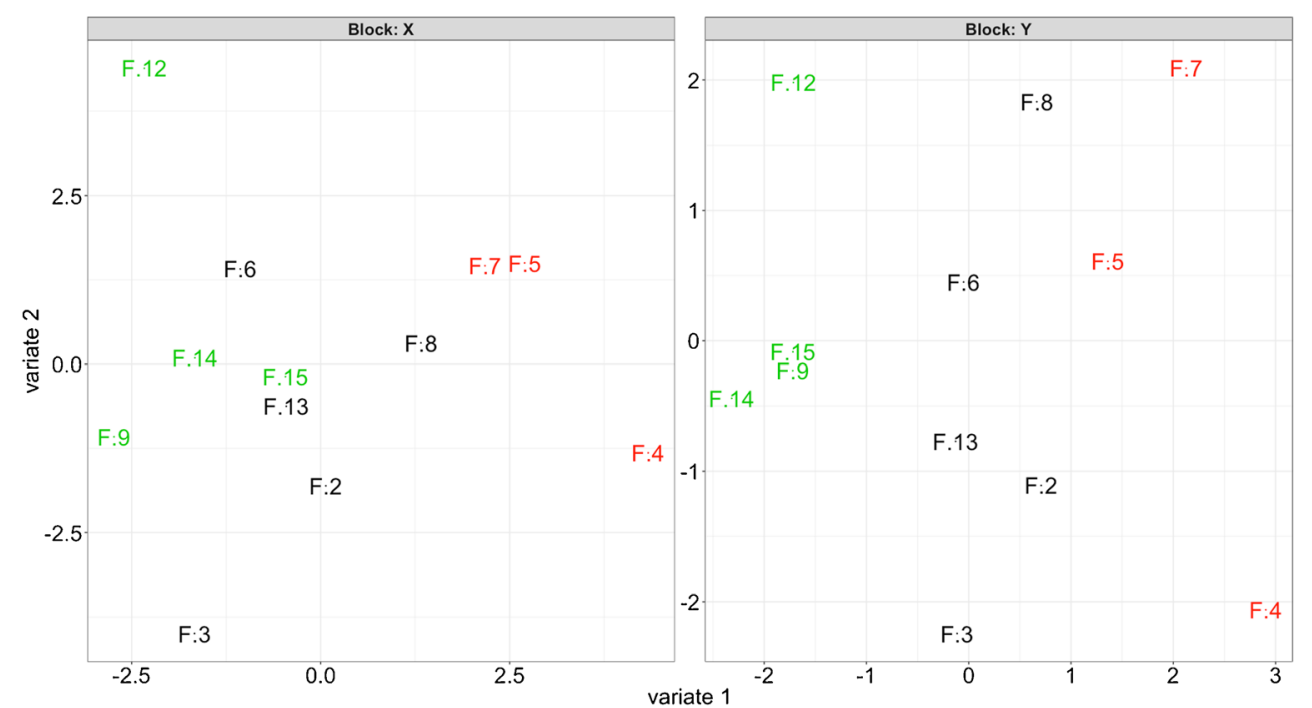


$€ /$ worker/year changing the range from 18 to $58 \mathrm{~K} € /$ year to 12-48 K€/year) and, to a smaller extent, independence from CAP subsidies (mean decreasing trend $=0.03$ every year changing the range from $0.6-0.7$ to $0.4-0.5$ ). Farms F4 and F7 even decreased their self-sufficient milk productivity (mean decreasing trend $=438 \mathrm{~kg}$ milk/ha/year changing the range from $3619-5677$ to $2558-2579 \mathrm{~kg}$ milk/ha/year) while farm 5 slightly increased it by $110 \mathrm{~kg}$ milk/ha/year every year. Efficiency was among the lowest in the sample and it slightly decreased for farm F5 (from 1.97 to 1.96) and increased for farms F4 and F7 (from 1.4-3.1 to 2.0-3.5). These trends suggest an increase in farm vulnerability during the conversion to organic. These farms followed a relatively conservative strategy: the percentage of maize remained relatively low (from 713 to $8-9 \%$ with a trend towards stability: $-0.4 \%$ every year), and the percentage of pasture remained high (from 87-91 to 78-92\%) although it tended to decrease slightly (mean decreasing trend $=1.3 \%$ every year). They implemented different strategies to distribute concentrates, which was initially relatively low: farm 4 increased use from 97 (in 2009) to $502 \mathrm{~kg} / \mathrm{LU} /$ year with a trend by $135 \mathrm{~kg} / \mathrm{LU}$ every year, farm F5 kept it relatively constant at 601 to $522 \mathrm{~kg} / \mathrm{LU} /$ year, and farm 7 decreased use from 318 to $55 \mathrm{~kg} / \mathrm{LU} /$ year with a trend by $43 \mathrm{~kg} / \mathrm{LU}$ every year. When farms F5 and F7 were conventional, they had a relatively high stocking rate (from 1.2-1.7) that decreased by $0.12 \mathrm{LU} / \mathrm{ha} /$ year (to $1.0-1.1 \mathrm{LU} / \mathrm{ha}$ ) as the percentage of heifers decreased (from 22-29 to 16-18\%) for farms F5 and F7, or remained relatively constant for farm F4 (from 15 to $16 \%$ ). These farms had the highest exposure to variability in effective rainfall in spring (range $=-1.68$ to $1.32 \mathrm{~mm} /$ year, mean $=-0.14, \mathrm{CV}=62 \%$ ).

The extent of the adaptation strategies implemented was relatively large considering the small sample size, as already shown by Weller and Bowling (2004) and Roberts et al. (2008) on British and Canadian organic dairy farms. Observed differences in these strategies had important and contrasting implications for farm vulnerability. Farm-level adaptation was required for the most vulnerable farms in the conventional stage, as demonstrated for Californian vineyards confronted with climate change (Nicholas and Durham 2012). These farms decreased their vulnerability the most during conversion to organic. Initially dissimilar to organic farming models, these farms successfully implemented adaptation strategies that focused on grazing and self-sufficient animal feeding, as Coquil et al. (2014) and Lebacq et al. (2015) observed for conventional dairy farms. Over the long term, the risks related to these strategies would be to widen farm nutrient deficits, especially for phosphorus, thereby slowly increasing farm vulnerability (Weller and Bowling, 2004; Roberts et al., 2008). That may be a reason why farms that were similar to organic farming models when conventional began in less vulnerable situations, and in some cases increased their degree of feed imports through concentrates. These farms seemed to have little room for improvement and implemented fairly conservative strategies. As a result, conversion to organic did not decrease their vulnerability much and even slightly decreased some of the vulnerability variables considered. These farmers had "recipes" that worked well for conventional farming which they may have repeated without adapting them to organic farming. Responding and adapting to change requires experimenting and learning at the individual level, as well as at the group level by sharing experiences with peers (Marshall et al. 2014). This stimulates individual creativity in how farm resources, specific regional advantages and the production context can be combined (Bouttes et al. 2018a).

The least vulnerable farms, once organic, were based on cost-effective management and self-sufficient animal feeding, with a major focus on pastures but they did not require increases in farm size to compensate for the decrease in productivity. This is consistent with Bouttes et al.'s (2018b) findings from a network of 51 organic dairy farms in France. This challenges the diversity argument made in most scientific articles on the mechanisms of adaptive capacity, resilience and vulnerability of agricultural systems (e.g. Darnhofer et al. 2010). Even in systems with little diversity, farmers need to consistently adjust land use and herd management intensities so as to reach expected trade-offs among productivity, economic efficiency, profitability per worker, and independence from CAP subsidies, as well as other aspects not considered in this study but which are of major importance in farmers' decision-making. For example, one farm similar to organic farming models when conventional invested the increased income provided by the conversion to organic and hired an employee to reduce the workload. This may improve the social component of farm vulnerability (Marshall et al. 2014), which is another type of trade-off that farmers consider to improve the balance between profitability per worker and their workload (Bouttes et al. 2018a).

\subsection{Adaptive capacity rather than exposure to risks first determines farm vulnerability}

Exposure to climatic risks varied among farms and over time. In 2008, mean daily effective rainfall (rainfall minus evapotranspiration) in spring ranged from -0.03 to $1.32 \mathrm{~mm}(\mathrm{CV}=$ $69 \%$ ). Over the entire study period, its mean yearly variability was high, ranging from -1.04 to $0.55 \mathrm{~mm}$. For example, over the years, mean daily effective rainfall in spring ranged from -1.35 to $0.58 \mathrm{~mm}$ for farm 12 and -1.31 to $1.32 \mathrm{~mm}$ for farm 4 , which reflects different exposures to spring droughts. In 2008 , effective rainfall in summer ranged from -1.45 to $0.67 \mathrm{~mm}(\mathrm{CV}=62 \%)$. Over the entire study period, its mean yearly variability was low, ranging from -1.18 to -0.34 . For example, over the years, mean daily effective rainfall in summer ranged from -2.04 to $0.31 \mathrm{~mm}$ for farm 12 and -1.57 to $-0.37 \mathrm{~mm}$ for farm 4 . However, the PLS regression revealed 
that only four (i.e. variability in effective rainfall in spring and summer, earliness of the growing season and heat stress) out of the six variables describing farm exposure to climatic variability were correlated with vulnerability variables. Overall, these exposure variables were not among the main determinants of the evolution of farm vulnerability, contrary to the variables describing farming practices (Fig. 4).

At the regional scale of this study, exposure to economic risks is considered equal among dairy farms but varies over time. The national price index for energy (IDELE 2017) varied from 109 in 2008 to 118 in 2013 (index = 100 in 2010), indicating an increasing trend, especially from 2009 to 2011, when the index increased by 32 points, after decreasing by 23 points from 2008 to 2009 . These variations tended to increase farm energy costs and likely the costs of other inputs as well (e.g. feed, organic fertilisers). The mean price of milk also varied considerably during the period, ranging from 299 to $422 € / t /$ year, with a coefficient of variation $(\mathrm{CV})$ of $15 \%$ among years and farms. During this period, conventional prices decreased by $31 € / t$ from 2008 to 2009 under the influence of the European milk crisis and increased by $47 € / t$ the following year. In 2011, these farmers began to receive organic milk prices; consequently, their prices increased by $76 € / \mathrm{t}$ from 2010 to 2011. In 2012 and across farms, the mean organic milk price premium corresponded to a $25 \%$ increase compared to year 2008. In parallel, the mean increase in economic efficiency was as high as $124 \%$ and the mean increase of profitability per worker was $54 \%$. This indicates that most farms benefited from their conversion to organic beyond the milk price premium thanks to the savings in operational costs allowed by the implementation of farming practices focused on grazing and self-sufficient animal feeding. Consequently, the variability of the milk price was poorly correlated with vulnerability variables (Fig. 4).

As shown for French organic dairy farms (Bouttes et al. 2018b), despite increasing uncertainty and variability in the production context (Wright 2011; IPCC 2013), interannual variability in climatic and economic conditions had less influence on vulnerability variables than farming practices before, during and after conversion to organic farming. The impacts of the changes in farming practices implemented exceeded far beyond those of the variability in climatic and economic conditions among farms. These results reveal that the extent to which farms can adapt to contextual changes remains large and can yield quick and significant impacts.

\section{Conclusion}

This study is the first to assess farm vulnerability during the conversion to organic farming. We analysed whether and how to decrease dairy farm vulnerability as a trade-off between self-sufficient milk productivity, economic efficiency, profitability per worker and independence from CAP subsidies when converting to organic farming, and the adaptation strategies that most decrease this vulnerability. We showed that inter-annual variability in climatic and economic conditions had less influence on vulnerability than farming practices before, during and after conversion to organic farming. The farms with the largest decrease in vulnerability were initially dissimilar to organic farming models in the Brittany context. They drastically changed from a crop-based, feedinput-dependent and productivity-centred strategy to a strategy focused on grazing and self-sufficient animal feeding. However, the statistical approach was fairly descriptive, and no significance tests were performed, mainly due to the small sample size. The small-sample survey was an initial step in understanding changes in vulnerability during the conversion to organic farming. As the trade-off analysis was based solely on researchers' viewpoints, future studies should include farmers' perceptions of vulnerability during the conversion to organic farming. These findings will help farm advisers adapt the support provided to farmers who are considering converting to organic farming.

Acknowledgments The authors wish to thank the farmers who generously gave their time for the interviews.

Funding This study was funded by INRA and the Midi-Pyrénées region as part of the ATARI project and Maëlys Bouttes's Ph.D. project, and by the French ANR Agrobiosphère program as part of the TATABOX project (ANR-13-AGRO-0006).

\section{Compliance with ethical standards}

Conflict of interest The authors declare that they have no conflict of interest.

Publisher's note Springer Nature remains neutral with regard to jurisdictional claims in published maps and institutional affiliations.

\section{References}

Agreste (2015) Bretagne Filière Lait

Bouttes M, Darnhofer I,Martin G (2018a) Converting to organic farming as a way to enhance adaptive capacity. Org Agr https://doi.org/10. 1007/s13165-018-0225-y

Bouttes M, San Cristobal M, Martin G (2018b) Vulnerability to climatic and economic variability is mainly driven by farmers' practices on French organic dairy farms. Eur J Agron 94:89-97. https://doi.org/ 10.1016/j.eja.2018.01.013

Brehon N-J (2009) L'Europe et la crise du lait : quelles régulations pour le secteur laitier?

Chantre E, Cardona A (2014) Trajectories of French field crop farmers moving toward sustainable farming practices: change, learning, and links with the advisory services. Agroecol Sustain Food Syst 38: 573-602. https://doi.org/10.1080/21683565.2013.876483

Coquil X, Béguin P, Dedieu B (2014) Transition to self-sufficient mixed crop-dairy farming systems. Renew Agric Food Syst 29:195-205. https://doi.org/10.1017/S1742170513000458 
Cranfield J, Henson S, Holliday J (2010) The motives, benefits, and problems of conversion to organic production. Agric Hum Values 27:291-306. https://doi.org/10.1007/s10460-009-9222-9

Darnhofer I, Bellon S, Dedieu B, Milestad R (2010) Adaptiveness to enhance the sustainability of farming systems. A review. Agron Sustain Dev 30:545-555. https://doi.org/10.1007/978-94-0070394-0_4

Doole GJ, Romera AJ (2015) Trade-offs between profit, production, and environmental footprint on pasture-based dairy farms in the Waikato region of New Zealand. Agric Syst 141:14-23. https://doi.org/10. 1016/j.agsy.2015.09.005

Falconnier GN, Descheemaeker K, Van Mourik TA et al (2015) Understanding farm trajectories and development pathways: two decades of change in southern Mali. Agric Syst 139:210-222. https://doi.org/10.1016/j.agsy.2015.07.005

Flaten O, Lien G, Ebbesvik M, Koesling M, Valle PS (2006) Do the new organic producers differ from the "old guard"? Empirical results from Norwegian dairy farming. Renew Agric Food Syst 21:174 182. https://doi.org/10.1079/RAF2005140

García-Martínez A, Olaizola A, Bernués A (2009) Trajectories of evolution and drivers of change in European mountain cattle farming systems. Animal 3:152-165. https://doi.org/10.1017/ S1751731108003297

IDELE (2017) IPAMPA lait de Vache. http://idele.fr/services/outils/ ipampa.html. Accessed 20 Oct 2017

IPCC (2013) Climate change 2013: the physical science basis. In: Stocker TF, Qin D, Plattner G-K, Tignor M, Allen SK, Boschung J, Nauels A, Xia Y, Bex V (ed) Contribution of Working Group I to the Fifth Assessment Report of the Intergovernmental Panel on Climate Change Cambridge, United Kingdom and New York, NY, USA

Kanter DR, Musumba M, Wood SLR, Palm C, Antle J, Balvanera P, Dale VH, Havlik P, Kline KL, Scholes RJ, Thornton P, Tittonell P, Andelman S (2016) Evaluating agricultural trade-offs in the age of sustainable development. Agric Syst 163:73-88. https://doi.org/10. 1016/j.agsy.2016.09.010

Klapwijk CJ, van Wijk MT, Rosenstock TS, van Asten P, Thornton PK, Giller KE (2014) Analysis of trade-offs in agricultural systems: current status and way forward. Curr Opin Environ Sustain 6:110-115. https://doi.org/10.1016/j.cosust.2013.11.012

Lamine C, Bellon S (2009) Conversion to organic farming: a multidimensional research object at the crossroads of agricultural and social sciences. A review. Agron Sustain Dev 29:97-112. https://doi.org/ 10.1051/agro:2008007
Lê Cao K-A, González I, Déjean S (2009) integrOmics: an R package to unravel relationships between two omics datasets. Bioinformatics 25:2855-2856. https://doi.org/10.1093/bioinformatics/btp515

Lebacq T, Baret PV, Stilmant D (2015) Role of input self-sufficiency in the economic and environmental sustainability of specialised dairy farms. Animal 9:544-552. https://doi.org/10.1017/ S1751731114002845

Marshall NA, Stokes CJ, Webb NP, Marshall PA, Lankester AJ (2014) Social vulnerability to climate change in primary producers: a typology approach. Agric Ecosyst Environ 186:86-93

Martin G, Magne M-A, Cristobal MS (2017) An integrated method to analyze farm vulnerability to climatic and economic variability according to farm configurations and farmers' adaptations. Front Plant Sci 8. https://doi.org/10.3389/fpls.2017.01483

Nicholas KA, Durham WH (2012) Farm-scale adaptation and vulnerability to environmental stresses: insights from winegrowing in Northern California. Glob Environ Chang 22:1-12. https://oi.org/ 10.1016/j.gloenvcha.2012.01.001

Roberts CJ, Lynch DH, Voroney RP, Martin RC, Juurlink SD (2008) Nutrient budgets of Ontario organic dairy farms. Can J Soil Sci 88:107-113. https://doi.org/10.4141/S06-056

Reed MS, Podesta G, Fazey I, Geeson N, Hessel R, Hubacek K, Letson D, Nainggolan D, Prell C, Rickenbach MG, Ritsema C, Schwilch G, Stringer LC, Thomas AD (2013) Combining analytical frameworks to assess livelihood vulnerability to climate change and analyse adaptation options. Ecol Econ 94:66-77. https://doi.org/10.1016/j. ecolecon.2013.07.007

Ripoll-Bosch R, Díez-Unquera B, Ruiz R, Villalba D, Molina E, Joy M, Olaizola A, Bernués A (2012) An integrated sustainability assessment of mediterranean sheep farms with different degrees of intensification. Agric Syst 105:46-56. https://doi.org/10.1016/j.agsy. 2011.10.003

Smit B, Wandel J (2006) Adaptation, adaptive capacity and vulnerability. Glob Environ Chang 16:282-292. https://doi.org/10.1016/j. gloenvcha.2006.03.008

Weller RF, Bowling PJ (2004) The performance and nutrient use efficiency of two contrasting systems of organic milk production. Biol Agric Hortic 22(3):261-270. https://doi.org/10.1080/01448765. 2004.9755289

Wright BD (2011) The economics of grain price volatility. Appl Econ Perspect Policy 33:32-58. https://doi.org/10.1093/aepp/ppq033 